\title{
Differing trends in the association between obesity and self-reported health in Portugal and Switzerland. Data from national health surveys 1992-2007
}

\author{
Pedro Marques-Vidal ${ }^{1 *}$, Paula Ravasco ${ }^{2}$ and Fred Paccaud ${ }^{1}$
}

\begin{abstract}
Background: The escalating prevalence of obesity might prompt obese subjects to consider themselves as normal, as this condition is gradually becoming as frequent as normal weight. In this study, we aimed to assess the trends in the associations between obesity and self-rated health in two countries.

Methods: Data from the Portuguese (years 1995-6, 1998-6 and 2005-6) and Swiss (1992-3, 1997, 2002 and 2007) National Health Surveys were used, corresponding to more than 130,000 adults (64,793 for Portugal and 65,829 for Switzerland). Body mass index and self-rated health were derived from self-reported data.

Results: Obesity levels were higher in Portugal (17.5\% in 2005-6 vs. 8.9\% in 2007 in Switzerland, $p<0.001)$ and increased in both countries. The prevalence of participants rating their health as "bad" or "very bad" was higher in Portugal than in Switzerland (21.8\% in 2005-6 vs 3.9\% in 2007, p < 0.001). In both countries, obese participants rated more frequently their health as "bad" or "very bad" than participants with regular weight. In Switzerland, the prevalence of "bad" or "very bad" rates among obese participants, increased from 6.5\% in 1992-3 to 9.8\% in 2007, while in Portugal it decreased from $41.3 \%$ to $32.3 \%$. After multivariate adjustment, the odds ratio (OR) of stating one self's health as "bad" or "very bad" among obese relative to normal weight participants, almost doubled in Switzerland: from 1.38 (95\% confidence interval, Cl: 1.01-1.87) in 1992-3 to 2.64 (95\% Cl: 2.14-3.26) in 2007, and similar findings were obtained after sample weighting. Conversely, no such trend was found in Portugal: 1.35 (95\% Cl: 1.231.48 ) in 1995-6 and 1.52 (95\% Cl: 1.37-1.70) in 2005-6.
\end{abstract}

Conclusion: Obesity is increasing in Switzerland and Portugal. Obesity is increasingly associated with poorer self-health ratings in Switzerland but not in Portugal.

Keywords: Obesity, Self-rated health, Population survey, Trends, Portugal, Switzerland

\section{Background}

Obesity has reached pandemic proportions [1,2], carries a significant health and economic burden $[3,4]$ and is associated with an increased mortality [5]. In order to be effective, public health campaigns against excess weight have to raise the awareness of the target population that obesity is an "unhealthy" condition, thus prompting adequate management procedures. Still, the association

\footnotetext{
* Correspondence: Pedro-Manuel.Marques-Vidal@chuv.ch

${ }^{1}$ Institute of Social and Preventive Medicine (IUMSP), CHUV and Faculty of biology and medicine, Lausanne, Switzerland

Full list of author information is available at the end of the article
}

between self-rated health and obesity status is not straightforward. Several studies showed that obesity is associated with a lower self-rated health [6,7], while other studies failed to find such a relationship $[8,9]$.

A recent study [10] showed no particular trends in the association between obesity and self-reported overall health in the USA. One explanation provided by the authors was that obesity was becoming increasingly "normal" (i.e. frequent) in the USA, a concept also suggested elsewhere [11]. This would make obese subjects feel they have a "normal", healthy status when comparing themselves against an increasingly obese population.

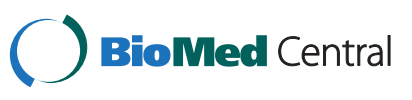


Still, whether this "normalization" by high obesity prevalence is true remains to be assessed.

Hence, in this study, we used data from National Health surveys to assess the association between obesity and self-reported health according to gender and age group in Portugal and Switzerland, two small European countries with a differing prevalence of obesity $[1,12,13]$. We also assessed the trends in the association between obesity and self-reported health for the period 1995-2005 (for Portugal) and 1992-2007 (for Switzerland).

\section{Methods}

\section{Portuguese health survey}

Portuguese data were provided upon request by the National Health Observatory (www.onsa.pt) (1995-6 and 1998-9) and the National Institute of Statistics (www.ine.pt) (2005-6). The methodology of the Portuguese national interview surveys has been described previously $[12,14]$. Briefly, the National Health Surveys were conducted between May 1995 and April 1996 (1995-6), October 1998 and September 1999 (1998-9) and February 2005 and January 2006 (2005-6). The sampling frame was built on census data and included all subjects living in individual housing during that period (collective housing such as hospitals, prisons, military barracks, or retirement houses was excluded). The sample was considered representative of the main regions of continental Portugal (North, Center, Lisbon region, Alentejo, and Algarve). In the 2005-6 survey the autonomous regions of the Azores and Madeira were also included, but not considered in the present analysis. The primary sampling unit (PSU) was the house, and data were derived from the population and housing census. Within each main region, two strata were defined: the freguesias (corresponding to counties) and, within the freguesias, geographically defined units of \pm 300 lodgings (240 in 2005-6). The PSUs were then randomly selected within each geographically defined unit. All subjects living in the sampling unit (house) were surveyed. All surveys were carried out in compliance with the Helsinki Declaration. Data were collected using face-to-face interviews by trained staff according to a standardized protocol [14], and quality control was maintained by reapplying (by a different interviewer) the same questionnaire to $10 \%$ of the initial sample. Participation rates (defined as the percentage of households who responded) as reported by the National Institute of Statistics were $88 \%$ in $1995-6,82 \%$ in $1998-9$ and $76 \%$ in $2005-6$.

\section{Swiss health survey}

Data from the four Swiss Health Surveys (SHS) were obtained from the Swiss federal bureau of statistics (www.bfs.admin.ch). The SHS is a cross-sectional, nationwide, population-based telephone survey conducted every 5 years since 1992 by the Federal Statistical Office of Switzerland under a mandate from the federal government [15]. To date, the survey has been carried out four times, in 1992-3, 1997, 2002 and 2007 and can be considered as representative of the Swiss population. The study population was chosen by stratified random sampling of a database of all private Swiss households with fixed-line telephones (as opposed to mobile phones). The first sampling stratum consisted of the seven main regions: West "Leman", West-Central "Mittelland", Northwest, Zurich, North-Eastern, Central and South. The second stratum consisted of the cantons, and the number of households drawn was proportional to the population of the canton. In some cantons, oversampling of households was performed to obtain accurate cantonal estimates. The third stratum consisted of the household. One member of the household was randomly selected in advance within all members aged 15 years and over. A letter inviting this selected household member to participate in the survey was sent to each sampled subject, who was contacted thereafter by phone and interviewed using computer-assisted telephone interview (CATI) software to manage dialling and data collection. Face-to-face interviews were organised for subjects older than 75 years. In the case of long-term absence of a sampled subject, a proxy interviewee was requested to provide answers on behalf of the pre-defined sampled person (approximately 3\% of households). The interviews were carried out in German, French or Italian, as appropriate. People who did not speak any of these three languages were excluded from the survey. Other criteria for exclusion were asylum seeker status, households without a fixed-line telephone, very poor health status and living in a nursing home [16]. The participation rate was $71 \%$ in $1992-3,85 \%$ in $1997,64 \%$ in 2002 , and $66 \%$ in 2007 . It is estimated that $<2 \%$ of households were excluded owing to these exclusion criteria. Details are available at http://www.bfs.admin.ch/ $\mathrm{bfs} /$ portal/fr/index/infothek/erhebungen_quellen/blank/ blank/ess/01.html.

\section{Data collected}

In both countries, height and weight were selfreported. Body mass index (BMI) was calculated and three categories were defined: normal $\left(\mathrm{BMI}<25 \mathrm{~kg} / \mathrm{m}^{2}\right)$, overweight $\left(25 \leq \mathrm{BMI}<30 \mathrm{~kg} / \mathrm{m}^{2}\right)$ and obese $(\mathrm{BMI} \geq$ $30 \mathrm{~kg} / \mathrm{m}^{2}$ ). Self-reported health was coded as "very good", "good", "fair", bad" and "very bad". Due to the small number of "very bad" answers, we grouped the answers "bad" and "very bad" and performed the multivariate analysis on this pooled group. 


\section{Statistical analysis}

Statistical analysis was conducted using SAS v.9.2 (SAS Inc., Cary, NC, USA). Quantitative variables were expressed as mean \pm standard deviation and qualitative variables as number of participants and (percentage). Bivariate comparisons were performed using Student $t$-test or a chi-square test for quantitative and qualitative variables, respectively. Multivariate analysis was performed for each country separately using logistic regression adjusting for gender, age, education, smoking status and geographic region. As several studies have reported differing associations between obesity status and selfrated health according to gender and age $[17,18]$, a similar analysis was conducted for each country stratifying

Table 1 Clinical characteristics of the participants, by country and survey year

\begin{tabular}{|c|c|c|c|c|c|}
\hline Country & Survey 1 & Survey 2 & Survey 3 & Survey 4 & Test \\
\hline Portugal (survey year) & $1995-6$ & $1998-9$ & $2005-6$ & & \\
\hline Sample size & 22,162 & 22,695 & 16,899 & & \\
\hline Women (\%) & $13,522(61.0)$ & $14,284(62.9)$ & $9923(58.7)$ & & $72.65^{* * *}$ \\
\hline $\mathrm{BMI}\left(\mathrm{kg} / \mathrm{m}^{2}\right)$ & $25.6 \pm 4.1$ & $25.9 \pm 4.2$ & $26.2 \pm 4.4$ & & $82.07^{* * *}$ \\
\hline \multicolumn{6}{|l|}{ BMI categories (\%) } \\
\hline Normal & $10,582(47.8)$ & $10,477(46.2)$ & $7293(43.2)$ & & \\
\hline Overweight & $8512(38.4)$ & $8776(38.7)$ & $6655(39.4)$ & & $129.5^{* * *}$ \\
\hline Obese & $3068(13.8)$ & $3442(15.2)$ & $2951(17.5)$ & & \\
\hline \multicolumn{6}{|l|}{ Educational level (\%) } \\
\hline Basic & $17,611(79.4)$ & $16,895(74.4)$ & $11,216(66.4)$ & & \\
\hline Secondary & $3249(14.7)$ & $4136(18.2)$ & $3965(23.4)$ & & $863.4^{* * *}$ \\
\hline University & $1302(5.9)$ & $1664(7.4)$ & $1718(10.2)$ & & \\
\hline Smokers (\%) & $3189(14.4)$ & $3379(14.9)$ & $2525(14.9)$ & & $3.10 \mathrm{NS}$ \\
\hline \multicolumn{6}{|l|}{ Self-rated health (\%) } \\
\hline Very good & $531(2.4)$ & $544(2.4)$ & $963(5.7)$ & & \\
\hline Good & $5567(25.1)$ & $6159(27.1)$ & $5291(31.3)$ & & $821.0^{* * *}$ \\
\hline Fair & $9385(42.4)$ & $9920(43.7)$ & $6965(41.2)$ & & \\
\hline Bad & $5232(23.6)$ & $4810(21.2)$ & $2793(16.5)$ & & \\
\hline Very bad & $1447(6.5)$ & $1262(5.6)$ & $887(5.3)$ & & \\
\hline Switzerland (survey year) & $1992-3$ & 1997 & 2002 & 2007 & \\
\hline Sample size & 14,521 & 12,470 & 18,904 & 17,869 & \\
\hline Women (\%) & $7946(54.7)$ & $6934(55.6)$ & $10,343(54.7)$ & $9857(55.2)$ & $3.12 \mathrm{NS}$ \\
\hline $\mathrm{BMI}\left(\mathrm{kg} / \mathrm{m}^{2}\right)$ & $23.6 \pm 3.8$ & $24.0 \pm 4.0$ & $24.4 \pm 4.1$ & $24.5 \pm 4.1$ & $142.9 * * *$ \\
\hline \multicolumn{6}{|l|}{ BMI categories (\%) } \\
\hline Normal & $10,091(69.5)$ & $8148(65.3)$ & $11,567(61.2)$ & $10,822(60.6)$ & \\
\hline Overweight & $3627(25.0)$ & $3448(27.7)$ & $5747(30.4)$ & $5459(30.6)$ & $386.0 * * *$ \\
\hline Obese & $803(5.5)$ & $874(7.0)$ & $1590(8.4)$ & $1588(8.9)$ & \\
\hline \multicolumn{6}{|l|}{ Educational level (\%) } \\
\hline Basic & $3081(21.2)$ & $2745(22.0)$ & $3632(19.2)$ & $2469(13.8)$ & \\
\hline Secondary & $8300(57.2)$ & $7576(60.8)$ & $12,081(63.9)$ & $10,518(58.9)$ & $1004.7^{* * *}$ \\
\hline University & $3140(21.6)$ & $2149(17.2)$ & $3191(16.9)$ & $4882(27.3)$ & \\
\hline Smokers (\%) & $4648(32.0)$ & 4209 (33.8) & $5770(30.5)$ & $4910(27.5)$ & $153.9^{* * *}$ \\
\hline \multicolumn{6}{|l|}{ Self-rated health (\%) } \\
\hline Very good & $4040(27.8)$ & $3270(26.2)$ & $4262(22.6)$ & $3517(19.7)$ & \\
\hline Good & $8127(56.0)$ & $7076(56.7)$ & $11729(62.1)$ & $11,648(65.2)$ & \\
\hline Fair & $1782(12.3)$ & $1612(12.9)$ & $2224(11.8)$ & $2005(11.2)$ & $449.1^{* * *}$ \\
\hline Bad & $488(3.4)$ & $419(3.4)$ & $586(3.1)$ & $578(3.2)$ & \\
\hline Very bad & $84(0.6)$ & $93(0.8)$ & $103(0.5)$ & $121(0.7)$ & \\
\hline
\end{tabular}


on gender and age groups and adjusting for the remaining variables. Results were expressed as odds ratio (OR) and 95\% confidence interval (CI). For Switzerland, a further adjustment on nationality was performed as it has been shown that prevalence of obesity differs according to country of origin [19]. Conversely, it was not possible to restrict the analysis to migrants as performed by others [8] due to small sample sizes. Finally, contrary to another study [10], no adjustment for race was performed as data collection regarding race or ethnicity is forbidden by law in both countries. Statistical significance was considered for $\mathrm{p}<0.05$.

\section{Results}

\section{Characteristics of the samples}

Overall, data from over 120,000 adult participants was analyzed; 64,793 for Portugal and 65,829 for Switzerland. The main clinical characteristics of the samples according to country and study year are summarized in Table 1 . In both countries, mean BMI and the prevalence of obesity increased with study year; an improvement in educational level was also noted. The prevalence of current smokers remained stable in Portugal and decreased in Switzerland. Self-rated health improved in Portugal, while in Switzerland the prevalence of participants rating their health as "very good" decreased, although the prevalence of participants rating their health as "good" or "very good" remained relatively stable (Table 1). Of interest, the prevalence of participants rating their health as "bad" or "very bad" was much higher in Portugal (21.8\% in 2005-6 vs. 3.9\% in 2007 for Switzerland).

\section{Association between obesity and self-rated health}

On bivariate analyses and after stratifying for study, obese subjects rated their health as "bad" or "very bad" more frequently than normal or overweight subjects, and similar findings were obtained when the analysis was stratified by gender, although the association tended to be stronger in women (Table 2). Interestingly, opposite trends were found regarding self-rated health: in Portugal, the percentage of obese subjects rating their health as "bad" or "very bad" decreased, while the opposite trend was found in Switzerland (Table 2).

In Switzerland, an increase in the odds of rating one self's health as "bad" or "very bad" among obese subjects was found; for instance, the 95\% CI of the OR for obese subjects in 2007 did not overlap with the 95\% CI for 1992-3 (Table 3). Similar albeit nonsignificant results were obtained after stratifying for gender: in men, the OR [95\% confidence interval] of rating one self's health as "bad" or "very bad" increased from 1.49 [0.97-2.30] in 1992-3 to 2.38 [1.79-3.16] in 2007; in women, the corresponding values were 1.32 [0.87-1.99] and 2.52 [1.94-3.29].
Table 2 Bivariate associations between body mass index categories and rating one self's health as "bad" or "very bad", stratified by country, gender and survey

\begin{tabular}{lccc}
\hline Survey year & $\mathbf{1 9 9 5 - 6}$ & $\mathbf{1 9 9 8 - 9}$ & $\mathbf{2 0 0 5 - 6}$ \\
\hline Portugal, all & & & \\
\hline Normal & 26.7 & 23.0 & 17.5 \\
\hline Overweight & 30.4 & 27.3 & 21.8 \\
\hline Obese & 41.3 & 36.7 & 32.3 \\
\hline Test & $238.5^{* * *}$ & $248.4^{* * *}$ & $271.8^{* * *}$ \\
\hline
\end{tabular}

\section{Portugal, men}

\begin{tabular}{lccc}
\hline Normal & 23.3 & 21.3 & 15.5 \\
\hline Overweight & 23.6 & 19.3 & 15.9 \\
\hline Obese & 29.1 & 24.0 & 24.2 \\
\hline Test & $16.1^{* * *}$ & $13.3^{* *}$ & $47.6^{* * *}$ \\
\hline Portugal, women & & &
\end{tabular}

Portugal, women

\begin{tabular}{lccc}
\hline Normal & 28.7 & 23.9 & 18.7 \\
\hline Overweight & 35.6 & 33.4 & 27.1 \\
\hline Obese & 47.6 & 43.0 & 37.4 \\
\hline Test & $255.6^{* * *}$ & $333.9^{* * *}$ & $255.4^{* * *}$ \\
\hline
\end{tabular}

\begin{tabular}{lllll}
\hline Survey year & $1992-3$ & 1997 & 2002 & 2007
\end{tabular}

\section{Switzerland, all}

\begin{tabular}{lcccc}
\hline Normal & 3.7 & 3.4 & 2.8 & 2.9 \\
\hline Overweight & 4.1 & 5.1 & 4.3 & 4.3 \\
\hline Obese & 6.5 & 6.8 & 7.6 & 9.8 \\
\hline Test & $15.8^{* * *}$ & $34.6^{* * *}$ & $88.5^{* * *}$ & $180.3^{* * *}$ \\
\hline
\end{tabular}

\section{Switzerland, men}

\begin{tabular}{lcccc}
\hline Normal & 3.4 & 2.9 & 2.6 & 3.2 \\
\hline Overweight & 3.4 & 3.6 & 3.9 & 3.5 \\
\hline Obese & 6.1 & 5.1 & 5.8 & 9.7 \\
\hline Test & $8.28^{*}$ & $6.09^{*}$ & $24.3^{* * *}$ & $75.3^{* * *}$
\end{tabular}

Switzerland, women

\begin{tabular}{lcccc}
\hline Normal & 3.9 & 3.7 & 2.9 & 2.7 \\
\hline Overweight & 5.3 & 7.1 & 4.8 & 5.4 \\
\hline Obese & 6.9 & 8.0 & 9.2 & 9.9 \\
\hline Test & $13.0^{* *}$ & $40.8^{* * *}$ & $86.7^{* * *}$ & $119.5^{* * *}$
\end{tabular}

Results are expressed as percentage of subjects rating their health as "bad" or "very bad". Statistical analysis conducted by chi-square stratifying on country, gender and survey: ${ }^{*}, \mathrm{p}<0.05 ;{ }^{* *}, \mathrm{p}<0.01 ;{ }^{* *}, \mathrm{p}<0.001$.

Conversely, no clear trend was observed for Portugal, as the 95\% CI for the 1995-6 and the 2005-6 surveys overlapped (Table 3 ). When the analysis was restricted to obese subjects, no significant trend $(p=0.23)$ to rate one self's health as "bad" or "very bad" was found. Similarly, in men, the OR [95\% confidence interval] of rating one self's health as "bad" or "very bad" increased from 1.02 [0.87-1.19] in 1995-6 to 1.30 [1.08-1.56] in 2005-6; in women, the corresponding values were 1.54 [1.38-1.72] and 1.66 [1.46-1.90]. Finally, splitting the participants as $<50$ or $\geq 50$ years of age showed that Portuguese obese women aged $\geq 50$ had a lower OR of rating their health 
Table 3 Multivariate adjusted association between body mass index categories and rating one self's health as "bad" or "very bad", stratified by country and survey

\begin{tabular}{|c|c|c|c|c|}
\hline & Survey 1 & Survey 2 & Survey 3 & Survey 4 \\
\hline Portugal & $1995-6$ & $1998-9$ & 2005-6 & \\
\hline Normal & 1 (ref.) & 1 (ref.) & 1 (ref.) & \\
\hline Overweight & $0.94(0.88-1.01)$ & $0.97(0.91-1.05)$ & $0.98(0.89-1.08)$ & \\
\hline Obese & $1.35(1.23-1.48)$ & $1.33(1.22-1.46)$ & $1.52(1.37-1.70)$ & \\
\hline Switzerland & $1992-3$ & 1997 & 2002 & 2007 \\
\hline Normal & 1 (ref.) & 1 (ref.) & 1 (ref.) & 1 (ref.) \\
\hline Overweight & $0.93(0.76-1.14)$ & $1.35(1.10-1.65)$ & $1.29(1.08-1.54)$ & $1.21(1.01-1.44)$ \\
\hline Obese & $1.38(1.01-1.87)$ & $1.58(1.17-2.14)$ & $2.22(1.78-2.78)$ & $2.64(2.14-3.26)$ \\
\hline
\end{tabular}

Results are expressed as multivariate adjusted odds ratio and (95\% confidence interval). Statistical analysis adjusting for age, gender, educational level, smoking status, geographical region (Portugal) and geographical region and Swiss nationality (Switzerland).

as "bad" or "very bad" than younger obese women, while no differences were found for Portuguese obese men or for Swiss participants (Table 4).

\section{Discussion}

There are few studies that assessed the trends in the association between obesity and self-rated health [10]. In this study, we analysed the trends for Portugal and Switzerland, two small countries with differing obesity levels. Our results indicate that in Switzerland, the association between obesity and low self-rated health increased, while no such trend was found in Portugal.

Table 4 Multivariate adjusted association between body mass index categories and rating one self's health as "bad" or "very bad", stratified by country, gender and two age groups

\begin{tabular}{|c|c|c|}
\hline Age group (years) & $18-49$ & $50+$ \\
\hline \multicolumn{3}{|l|}{ Portugal, men } \\
\hline Normal & 1 (ref.) & 1 (ref.) \\
\hline Overweight & $0.69(0.57-0.84)$ & $0.81(0.75-0.88)$ \\
\hline Obese & $0.89(0.67-1.17)$ & $1.05(0.95-1.17)$ \\
\hline \multicolumn{3}{|l|}{ Portugal, women } \\
\hline Normal & 1 (ref.) & 1 (ref.) \\
\hline Overweight & $1.26(1.12-1.42)$ & $1.02(0.96-1.08)$ \\
\hline Obese & $2.01(1.75-2.32)$ & $1.49(1.38-1.61)$ \\
\hline \multicolumn{3}{|l|}{ Switzerland, men } \\
\hline Normal & 1 (ref.) & 1 (ref.) \\
\hline Overweight & $1.09(0.87-1.38)$ & $0.93(0.78-1.11)$ \\
\hline Obese & $2.20(1.56-3.10)$ & $1.58(1.25-1.98)$ \\
\hline \multicolumn{3}{|l|}{ Switzerland, women } \\
\hline Normal & 1 (ref.) & 1 (ref.) \\
\hline Overweight & $1.67(1.32-2.11)$ & $1.26(1.09-1.47)$ \\
\hline Obese & $2.23(1.59-3.12)$ & $2.22(1.85-2.66)$ \\
\hline
\end{tabular}

Results are expressed as multivariate adjusted odds ratio and ( $95 \%$ confidence interval). Statistical analysis adjusting for age, gender, geographical region, educational level, smoking status, survey year, geographical region (Portugal) and geographical region and Swiss nationality (Switzerland).
Portuguese rated their health as "bad" or very bad" much more frequently than Swiss. These findings are in agreement with a previous study conducted in Europe [20] which showed consistent differences in self-health ratings, although no information regarding Portugal or Switzerland was available. Interestingly, in the European study, the regional differences persisted after adjusting for individual socio-economic data, suggesting that other factors might be at play. A study conducted in Sweden also showed no interaction between socio-economic status and obesity on self-rated health [21]. Overall, it is likely that the differences in socio-economic variables between Portugal and Switzerland might not fully account for the differences in low self-rated health, but further studies are needed to assess this point.

In both countries, obese subjects rated more frequently their health as "bad" or "very bad" than normal weight subjects, and this association remained significant after multivariate adjustment. These findings are in agreement with the literature $[6,7,22]$, and the reasons are probably due to the fact that obesity is associated with increased objective health problems $[3,4]$. Also in agreement with other studies [10,23], Portuguese obese women were more likely to rate their health as "bad" or "very bad" than obese men, but no between-gender differences were found among Swiss obese. One possible reason for a lower health rating among women is a stronger social pressure to be thin $[24,25]$, but it is rather unlikely that this could explain the differences between countries. Overall, our results indicate that obese women have a lower self-rated health than men in Portugal but not in Switzerland, and further studies are needed to better understand the differences between countries.

The prevalence of obesity in Portugal was almost twice higher than in Switzerland. Still, compared to their normal weight counterparts, Swiss obese were more likely to rate their health as "bad" or "very bad" than Portuguese. Our results speak against one of the explanations for the lack of increase in the association between 
obesity and self-reported overall health in the USA, i.e. that obese subjects feel they have a "normal", healthy status when comparing themselves against an increasingly obese population [10,11]. An alternative explanation would be societal or cultural differences regarding body image and health, the Swiss being more concerned than other populations [26,27]. Further, several authors suggested that the association between overweight or obesity status and self-rated health varies according to gender and age [23], but the results were inconsistent. For instance, a positive association between obesity and low self-rated health was found among subjects aged 50+ in Greece [17], while in Spain this association was found among subjects aged less than 50 [18]. In this study, with the exception of Portuguese obese women, no clear differences between subjects aged $<50$ or $\geq 50$ years were found for Switzerland, and these differences were cancelled after stratifying the participants in three age groups $(\leq 44,45$ to 64 and $\geq 65$ years, Table 5) [23]. Thus, our results indicate that, contrary to other countries, there appears to be no clear generational or age differences in rating one's health among obese subjects in Portugal or Switzerland, but further studies are needed to better assess this point.

This study has several limitations worth acknowledging. First, height and weight were self reported, leading to a possible underestimation of obesity levels and to an overestimation of the association between obesity and low self-rated health, as only the most obese participants will actually be considered as obese. Still, a recent study comparing self-reported and measured data suggested that the magnitude of the BMI underestimation bias decreases with time [28]. If confirmed, this would increase the difference in ORs between the earliest and the latest surveys, as the earlier values would be overestimated and the latest closer to the "true" values. It should be also noted that other studies relied on self-reported BMI data $[10,29]$. Second, it has been suggested that reliability of self-rated health is low, namely among disadvantaged US adults sociodemographic groups [30]. Still, self-rated health has been shown to be consistently associated with health behaviours [31,32] and outcomes in several studies, and in our multivariate analyses we systematically adjusted for educational level (a proxy of sociodemographic status). Further, as the change in selfrated health can occur either towards an improvement or a worsening, this lower reliability might increase the variance (95\% confidence interval) of the association but not create a trend by itself. Third, one might question the representativeness of the Portuguese data, as in the 2005-6 survey only $15 \%$ of the sample smoked. This relatively low value might be explained by the fact that the overall smoking prevalence in Portugal is estimated at $19.7 \%$ and that Azores (smoking prevalence 24.5\%) and Madeira (20.3\%) were excluded from the analysis. Also, this value is close to the one reported in another Portuguese study (16.3\%) [33]. Hence, we do believe that the smoking prevalence reported in our study actually

Table 5 Multivariate adjusted association between body mass index categories and rating one self's health as "bad" or "very bad", stratified by country, gender and three age groups

\begin{tabular}{|c|c|c|c|}
\hline Age group (years) & $18-44$ & $45-64$ & $65+$ \\
\hline \multicolumn{4}{|l|}{ Portugal, men } \\
\hline Normal & 1 (ref.) & 1 (ref.) & 1 (ref.) \\
\hline Overweight & $0.64(0.50-0.82)$ & $0.82(0.72-0.92)$ & $0.86(0.78-0.96)$ \\
\hline Obese & $0.83(0.57-1.21)$ & $1.08(0.93-1.26)$ & $1.19(1.03-1.38)$ \\
\hline \multicolumn{4}{|l|}{ Portugal, women } \\
\hline Normal & 1 (ref.) & 1 (ref.) & 1 (ref.) \\
\hline Overweight & $1.23(1.06-1.43)$ & $1.06(0.97-1.15)$ & $1.09(1.00-1.19)$ \\
\hline Obese & $1.78(1.47-2.14)$ & $1.58(1.43-1.74)$ & $1.75(1.57-1.96)$ \\
\hline \multicolumn{4}{|l|}{ Switzerland, men } \\
\hline Normal & 1 (ref.) & 1 (ref.) & 1 (ref.) \\
\hline Overweight & $1.16(0.89-1.52)$ & $0.96(0.77-1.19)$ & $0.86(0.67-1.11)$ \\
\hline Obese & $2.41(1.62-3.58)$ & $1.63(1.23-2.16)$ & $1.52(1.08-2.13)$ \\
\hline \multicolumn{4}{|l|}{ Switzerland, women } \\
\hline Normal & 1 (ref.) & 1 (ref.) & 1 (ref.) \\
\hline Overweight & $1.72(1.32-2.25)$ & $1.39(1.13-1.70)$ & $1.16(0.95-1.42)$ \\
\hline Obese & $2.09(1.38-3.15)$ & $2.27(1.76-2.92)$ & $2.12(1.66-2.70)$ \\
\hline
\end{tabular}

Results are expressed as multivariate adjusted odds ratio and (95\% confidence interval). Statistical analysis adjusting for age, gender, geographical region, educational level, smoking status and survey. A further adjustment on geographical region (Portugal) or on geographical region and Swiss nationality (Switzerland) was performed. 
reflects the true prevalence of smoking in Portugal and that the sample can be considered as representative of the population of mainland Portugal. The main strengths of this study is that it uses nationally representative samples and that the data has been collected using the same standardized methodology throughout time. Finally, the purpose of this study was to assess the trends in the associations between obesity and self-rated health separately for Portugal and Switzerland, not to compare the self-rated health status between countries. Hence, it is likely that differing health status or cultural perceptions might explain the fact that the same person with the same health would be rate her/his health as good/fair in one country and as bad in the other, but further studies are needed to assess this point.

\section{Conclusion}

In summary, our results confirm that obese subjects tend to self-rate their health status as "bad" or "very bad" more frequently, but this lower rating does not seem to be influenced by the prevalence of obesity.

\section{Competing interests}

The authors report no conflict of interest.

\section{Authors' contributions}

PMV made the statistical analysis and wrote part of the article; FP and PR revised the article for important intellectual content and wrote part of the article. PMV had full access to the data and is the guarantor of the study. All authors read and approved the final manuscript.

\section{Acknowledgements}

Funding: This study was partially supported by a Grant from the "Fundação para a Ciência e Tecnologia - Portugal" (RUN 437).

\section{Author details}

'Institute of Social and Preventive Medicine (IUMSP), CHUV and Faculty of biology and medicine, Lausanne, Switzerland. ${ }^{2}$ Unidade de Nutrição e Metabolismo, Instituto de Medicina Molecular, Faculdade de Medicina da Universidade de Lisboa, Lisbon, Portugal.

Received: 25 January 2012 Accepted: 5 June 2012 Published: 1 August 2012

\section{References}

1. Finucane MM, Stevens GA, Cowan MJ, Danaei G, Lin JK, Paciorek CJ, et al: (Eds):National, regional, and global trends in body-mass index since 1980: systematic analysis of health examination surveys and epidemiological studies with 960 country-years and 9.1 million participants. In. Lancet 2011, 377:557-567.

2. International Obesity Task Force: Obesity prevalence worldwide; 2011. http:// www.iaso.org/iotf/obesity/ Assessed 29-1-2011.

3. Allender S, Rayner M: The burden of overweight and obesity-related ill health in the UK. Obes Rev 2007, 8:467-473.

4. Davin C, Vollenweider P, Waeber G, Paccaud F, Marques-Vidal P: Cardiovascular risk factors attributable to obesity and overweight in Switzerland. Nutr Metab Cardiovasc Dis; 2011.

5. Prospective Studies Collaboration: Body-mass index and cause-specific mortality in 900000 adults: collaborative analyses of 57 prospective studies. Lancet 2009, 373:1083-1096.

6. Prosper MH, Moczulski VL, Qureshi A: Obesity as a predictor of self-rated health. Am J Health Behav 2009, 33:319-329.

7. Trakas K, Oh Pl, Singh S, Risebrough N, Shear NH: The health status of obese individuals in Canada. Int J Obes Relat Metab Disord 2001, 25:662-668.
8. Kepka D, Ayala GX, Cherrington A: Do Latino immigrants link self-rated health with BMI and health behaviors? Am J Health Behav 2007, 31:535-544

9. Flodmark CE: The happy obese child. Int J Obes (Lond) 2005, 29(Suppl 2):S31-S33.

10. Macmillan R, Duke N, Oakes JM, Liao W: Trends in the association of obesity and self-reported overall health in 30 years of the integrated health interview series. Obesity (Silver Spring) 2011 19:1103-1105.

11. Burke MA, Heiland FW, Nadler CM: From "overweight" to "about right": evidence of a generational shift in body weight norms. Obesity (Silver Spring) 2010, 18:1226-1234.

12. Marques-Vidal P, Dias CM: Trends in overweight and obesity in Portugal: the National Health Surveys 1995-6 and 1998-9. Obes Res 2005, 13:1141-1145.

13. Marques-Vidal P, Bovet P, Paccaud F, Chiolero A: Changes of overweight and obesity in the adult Swiss population according to educational level, from 1992 to 2007. BMC Publ Health 2010, 10:87.

14. Instituto Nacional de Estatística IP: Inquérito nacional de saúde 2005/ 2006. Lisboa, Portugal: Instituto Nacional de Saúde Doutor Ricardo Jorge IP; 2009:1-330.

15. Calmonte R, Galati-Petrecca M, Lieberherr R, Neuhaus M, Kahlmeier S: Gesundheit und Gesundheitsverhalten in der Schweiz 1992-2002. Neuchâtel, Switzerland: Schweizerische Gesundheitsbefragung; 2005. Bundesamt für Statistik.

16. IHA-GFK: Schweizerische Gesundheitsbefragung SGB 2002 - Schlussbericht zur Datenerhebung. Neuchâtel, Switzerland: Bundesamt für Statistik; 2003.

17. Darviri C, Artemiadis AK, Tigani X, Alexopoulos EC: Lifestyle and self-rated health: a cross-sectional study of 3,601 citizens of Athens, Greece. BMC Public Health 2011, 11:619.

18. Girón P: Determinants of self-rated health in Spain: differences by age groups for adults. Eur J Public Health 2010, 22:36-40.

19. Marques-Vidal P, Vollenweider P, Waeber G, Paccaud F: Prevalence of overweight and obesity among migrants in Switzerland: association with country of origin. Public Health Nutr 2011, 14:1148-1156.

20. Gray L, Merlo J, Mindell J, Hallqvist J, Tafforeau J, O'Reilly D, et al: International differences in self-reported health measures in 33 major metropolitan areas in Europe. Eur J Public Health 2010, 22:40-47

21. Månsson NO, Merlo J: The relation between self-rated health, socioeconomic status, body mass index and disability pension among middle-aged men. Eur J Epidemiol 2001, 17:65-69.

22. Okosun IS, Choi S, Matamoros T, Dever GE: Obesity is associated with reduced self-rated general health status: evidence from a representative sample of white, black, and Hispanic Americans. Prev Med 2001, 32:429-436.

23. Imai K, Gregg EW, Chen YJ, Zhang P, de Rekeneire N, Williamson DF: The association of BMI with functional status and self-rated health in US adults. Obesity (Silver Spring) 2008, 16:402-408.

24. Brewis AA, Hruschka DJ, Wutich A: Vulnerability to fat-stigma in women's everyday relationships. Soc Sci Med 2011, 73:491-497.

25. Field AE, Austin SB, Camargo CA Jr, Taylor CB, Striegel-Moore RH, Loud KJ, et al: Exposure to the mass media, body shape concerns, and use of supplements to improve weight and shape among male and female adolescents. Pediatrics 2005, 116:e214-e220.

26. Alwan $H$, Viswanathan B, Paccaud F, Bovet P: Is accurate perception of body image associated with appropriate weight-control behavior among adolescents of the Seychelles. J Obes 2011, 201(1):817242.

27. Jaeger I: Habitudes alimentaires et image corporelle chez des étudiants de deuxième année de gymnase à Lausanne [Food habits and body image of students in Lausanne]. Rev Med Suisse 2008, 4:1432-1435.

28. Gorber SC, Tremblay M, Moher D, Gorber B: A comparison of direct vs. self-report measures for assessing height, weight and body mass index: a systematic review. Obes Rev 2007, 8:307-326.

29. Ford ES, Moriarty DG, Zack MM, Mokdad AH, Chapman DP: Self-reported body mass index and health-related quality of life: findings from the Behavioral Risk Factor Surveillance System. Obes Res 2001, 9:21-31. 
30. Zajacova A, Dowd JB: Reliability of Self-rated Health in US Adults. Am J Epidemiol 2011, 174:977-983.

31. Rohrer JE, Young R, Sicola V, Houston M: Overall self-rated health: a new quality indicator for primary care. J Eval Clin Pract 2007, 13:150-153.

32. Freyer-Adam J, Gaertner B, Tobschall S, John U: Health risk factors and selfrated health among job-seekers. BMC Publ Health 2011, 11:659

33. Perdigao C, Rocha E, Duarte JS, Santos A, Macedo A: Prevalence and distribution of the main cardiovascular risk factors in Portugal-the AMALIA study. Rev Port Cardiol 2011, 30:393-432.

doi:10.1186/1471-2458-12-588

Cite this article as: Marques-Vidal et al.: Differing trends in the association between obesity and self-reported health in Portugal and Switzerland. Data from national health surveys 1992-2007. BMC Public Health 2012 12:588.

\section{Submit your next manuscript to BioMed Central and take full advantage of:}

- Convenient online submission

- Thorough peer review

- No space constraints or color figure charges

- Immediate publication on acceptance

- Inclusion in PubMed, CAS, Scopus and Google Scholar

- Research which is freely available for redistribution 